\title{
Oral Cavity Adenoid Cystic Carcinoma
}

National Cancer Institute

\section{Source}

National Cancer Institute. Oral Cavity Adenoid Cystic Carcinoma. NCI Thesaurus. Code C8179.

An adenoid cystic carcinoma arising from the minor salivary glands in the oral cavity. 